\title{
Case of unrecognised food bone ingestion with dual site intestinal perforations
}

\author{
Aishah Coyte, ${ }^{1}$ Jamel Tahar Aïssa, ${ }^{1}$ Hoey C Koh, ${ }^{2}$ Graham Mackay ${ }^{1}$
}

${ }^{1}$ Glasgow Royal Infirmary, Glasgow, UK

${ }^{2}$ Victoria Infirmary, Glasgow, UK

\section{Correspondence to} Dr Aishah Coyte, aishahcoyte@gmail.com

Accepted 1 May 2016

\section{SUMMARY}

Food bone perforation of the bowel is a relatively rare diagnosis. Its presentation is non-specific and often misdiagnosed. We present a case where a food bone perforation in both the large and small bowel was diagnosed on CT scan. A successful outcome was achieved with surgical treatment.

\section{BACKGROUND}

Incidental ingestion of a foreign body is common. Intestinal perforation, as a result, occurs in $<1 \%{ }^{1}$ of foreign body ingestions, and often poses a diagnostic challenge. Patients often do not remember ingesting the object, and the clinical picture often resembles that of commoner conditions such as appendicitis and diverticulitis. ${ }^{2-5}$

\section{CASE PRESENTATION}

A 76-year-old man presented to our acute surgical unit-after having been referred to us by his general practitioner-with 6 weeks of intermittent lower abdominal pain, vomiting, anorexia, and febrile episodes. He had been treated for a urinary tract infection by his general practitioner, with no improvement. The patient's medical history included diverticular disease diagnosed on sigmoidoscopy, and a $5.6 \mathrm{~cm}$ abdominal aortic aneurysm. The patient was haemodynamically stable with a soft abdomen, left iliac fossa tenderness, and localised peritonism.

\section{INVESTIGATIONS}

1. Plain erect chest and abdominal X-rays on admission were unremarkable.
2. Blood results showed raised inflammatory markers-white cell count $12.6 \times 10^{9} / \mathrm{L}$ and C reactive protein $120 \mathrm{mg} / \mathrm{L}$.

3. CT scan of abdomen/pelvis (figure 1) was performed to exclude complicated diverticulitis (eg, paracolic collection or abscess).

\section{DIFFERENTIAL DIAGNOSIS}

Given the history of diverticular disease, the patient was started on intravenous antibiotics as treatment for presumed acute diverticulitis. The CT scan suggested intestinal perforation secondary to an ingested bone.

\section{TREATMENT}

On the basis of the findings of the CT scan and his persistent pain and localised peritonism, the patient was taken to the operating theatre. Initially, a laparoscopy was performed. There was no gross purulent or faecal peritonitis. An inflammatory mass was identified involving loops of small bowel densely adherent to the anterior abdominal wall and sigmoid colon. The adhesions between bowel loops were too dense to complete the procedure safely using a laparoscopic approach. After converting to an open procedure, a loop of mid-jejunum and sigmoid colon were found to be inseparable and were, therefore, resected en-bloc. There was no macroscopic evidence of diverticular disease in the remaining healthy left colon.

\section{OUTCOME AND FOLLOW-UP}

The patient made an uncomplicated postoperative recovery and was discharged home on day 6 .
To cite: Coyte A, Tahar Aïssa J, Koh HC, et al. BMJ Case Rep Published online: [please include Day Month Year] doi:10.1136/bcr-2015213767
A

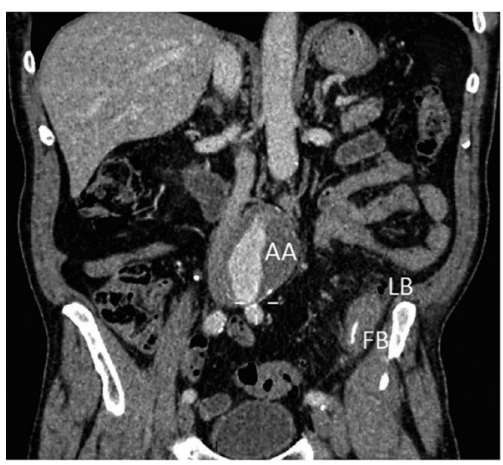

B

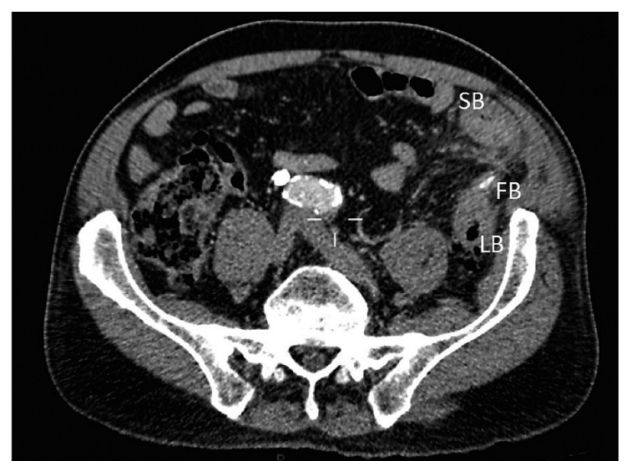

Figure $1 \mathrm{CT}$ scan showed a $5 \mathrm{~cm}$ long, fine linear food bone in the left iliac fossa. (A) Coronal view of inferior aspect of the food bone transversing the posterior colon wall. AA also seen. (B) Axial view of superior aspect of food bone showing penetration of the colon anteriorly with associated $S B$ thickening and mesenteric stranding. AA, aortic aneurysm; FB, foreign body; LB, large bowel; SB, small bowel. 


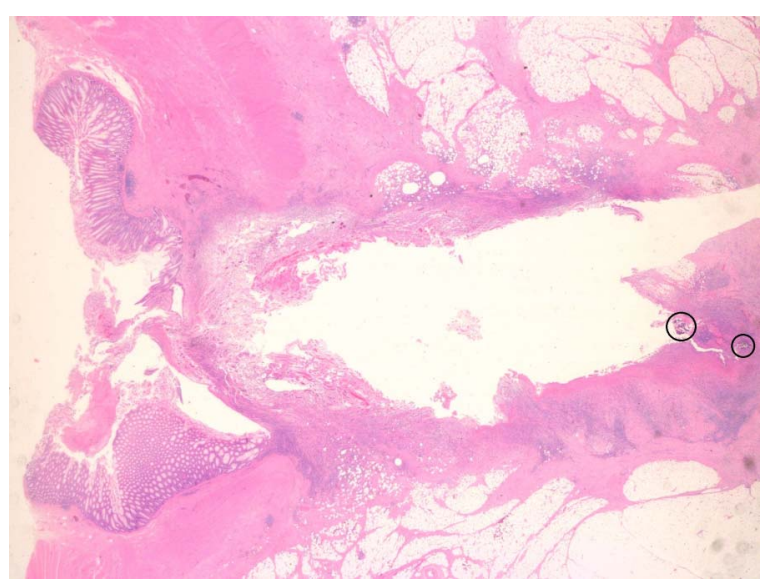

Figure 2 Histology from the point in the large bowel where food bone was removed. In the centre, running from left to right, there is a full-thickness cartilage defect through visible mucosa and underlying submucosa, muscularis propria, and adipose tissue. Black circles mark fragments of calcified material.

Histology (figure 2) confirmed the presence of a $5 \mathrm{~cm}$ long foreign body, a chicken bone that had perforated through the small bowel via a diverticulum in the sigmoid colon.

\section{DISCUSSION}

Bowel perforation from a foreign body is relatively rare. Fish or chicken bones, and toothpicks are the usual culprits. ${ }^{6}$ The

\section{Learning points}

- Perforations caused by foreign body ingestion are often non-specific and misdiagnoses such as diverticulitis, perforated peptic ulcer, and acute appendicitis are common.

- As in our case, there is often no recollection of food bone ingestion. The diagnosis is most commonly made on radiological imaging or intraoperatively. This case demonstrates the utility of $\mathrm{CT}$ imaging in accurately diagnosing foreign body ingestion as the cause of the patient's symptoms.

- The patient's symptoms were over a prolonged period of 6 weeks. This is in keeping with the bone becoming lodged in a sigmoid diverticulum and causing a perforation through local trauma. It is likely that a loop of small bowel became adherent to the local inflammation in the sigmoid colon and then the bone eroded secondarily into the small bowel.

- The localised inflammatory mass protected the patient from developing generalised peritonitis. In this setting, a primary resection and anastomosis can be considered to be in accordance with the management approach to this case. Other risk factors for anastomotic leakage should be taken into account before deciding whether to perform as anastomosis as part of the procedure, for example, age, anastomotic location, nutritional status, physiological compromise, etc. commonest sites of abdominal perforation are areas of narrow lumen and high angulation such as the terminal ileum and rectosigmoid junction. ${ }^{67}$ Risk factors for foreign bone ingestion are use of dentures, prison inmates, alcoholics, psychiatric patients, children, dress makers, carpenters, and previous bowel pathology. 268

The differential diagnosis commonly includes acute diverticulitis, acute appendicitis, and acute abdominal pain from unknown causes. ${ }^{2-5}$ Small bowel and large bowel perforations present differently. Interestingly, the patient presented with symptoms most commonly associated with a sealed large bowel perforation $^{6}$ (prolonged history of abdominal pain and with no free air demonstrated). Most patients have no recollection of food bone ingestion and the diagnosis is most commonly made on CT scan or intraoperativley. 67910

There are no guidelines for the management of foreign bodies in the lower gastrointestinal tract. Case reports describe managing patients non-operatively with antibiotics or with surgery, as in this case. ${ }^{2}$ There are cases reporting the use of laparoscopy to manage foreign body perforations. ${ }^{11}$ We were unable to do so in our case as we felt it was unsafe to proceed with the initial laparoscopic findings. Other factors can influence the suitability for a laparoscopic procedure such as operator experience and perforation site.

This is the only published case we know of with a large and small bowel perforation caused by an ingested food bone.

Acknowledgements Histology photo credit to Dr A. Oakley, Queen Elizabeth University Hospital, Glasgow.

Contributors AC and JTA researched and wrote the case report under the supervision of HCK and GM.

Competing interests None declared.

Patient consent Obtained.

Provenance and peer review Not commissioned; externally peer reviewed.

\section{REFERENCES}

1 Velitchkov NG, Grigorov GI, Losanoff JE, et al. Ingested foreign bodies of the gastrointestinal tract: retrospective analysis of 542 cases. World J Surg 1996;20:1001-5.

2 Rodríguez-Hermosa JI, Codina-Cazador A, Sirvent JM, et al. Surgically treated perforations of the gastrointestinal tract caused by ingested foreign bodies. Colorectal Dis 2008;10:701-7.

3 Wu CX, Wu BQ, et al. Rare case of omentum-wrapped abscess caused by a fish bone penetrating the terminal ileum. World J Gastroenterol 2014;20:11456-9.

4 Sarmast AH, Showkat HI, Patloo AM, et al. Gastrointestinal tract perforations due to ingested foreign bodies; a review of 21 cases. BJMP 2012;5:a529.

5 Yao CC, Yang CC, Liew SC, et al. Small bowel perforation caused by a sharp bone: laparoscopic diagnosis and treatment. Surg Laparosc Endosc Percutan Tech 1999;9:226-7

6 Goh BK, Chow PK, Quah HM, et al. Perforation of the gastrointestinal tract secondary to ingestion of foreign bodies. World J Surg 2006;30:372-7.

7 Hsu SD, Chan DC, Liu YC. Small-bowel perforation caused by fish bone. World J Gastroenterol 2005:11:1884-5.

8 Pinero Madrona A, Fernández Hernández JA, Carrasco Prats $M$, et al. Intestinal perforation by foreign bodies. Eur J Surg 2000;166:307-9.

9 Emir S, Özkan Z, Altınsoy HB, et al. Ingested bone fragment in the bowel: two cases and a review of the literature. World J Clin Cases 2013:1:212-16.

10 Goh BK, Tan YM, Lin SE, et al. CT in the preoperative diagnosis of fish bone perforation of the gastrointestinal tract. Am J Roentgenol 2006;187:710-4.

11 Birindelli A, Tugnoli G, Biscardi A, et al. Retroperitoneal colonic perforation from a foreign body: "cannibalization" effect of a toothpick: video vignette. Colorectal Dis 2016:8:319-21. 
Copyright 2016 BMJ Publishing Group. All rights reserved. For permission to reuse any of this content visit http://group.bmj.com/group/rights-licensing/permissions.

BMJ Case Report Fellows may re-use this article for personal use and teaching without any further permission.

Become a Fellow of BMJ Case Reports today and you can:

- Submit as many cases as you like

- Enjoy fast sympathetic peer review and rapid publication of accepted articles

- Access all the published articles

- Re-use any of the published material for personal use and teaching without further permission

For information on Institutional Fellowships contact consortiasales@bmjgroup.com

Visit casereports.bmj.com for more articles like this and to become a Fellow 